\title{
Anticipatory contrast: Within-subjects analysis
}

\author{
CHARLES F. FLAHERTY and GRACE A. ROWAN \\ Rutgers University, New Brunswick, New Jersey
}

\begin{abstract}
Contrast in consummatory behavior occurs readily when a less preferred substance follows a preferred substance. A previous experiment indicated that contrast in consummatory behavior may also develop when a less preferred substance precedes a preferred substance in brief daily exposures. In the present experiment, the same animals sometimes received $0.15 \%$ saccharin followed, 15 sec later, by $32 \%$ sucrose (.15-32) and sometimes received $0.15 \%$ saccharin followed by the same $0.15 \%$ saccharin solution (.15-.15). One solution pair was given each day, and the two conditions, .15-32 and .15-.15, occurred in alternation across days. The two different solution conditions were correlated with different cues. Saccharin intake from the first tube was lower when the second tube contained $32 \%$ sucrose than when it contained $.15 \%$ saccharin, both in original discrimination training and following a reversal of the cue-solution pairings. These results support the conclusion that contrast in this situation is based on the anticipation of the impending $32 \%$ sucrose each day, rather than on a retrograde comparison with the $32 \%$ sucrose received the previous day. These data are considered in terms of Pavlovian conditioning outcomes when the $\mathrm{CS}$ is a stimulus with hedonic value.
\end{abstract}

Contrast effects, exaggerated responding apparently based on the opportunity to compare different levels of reward, are ubiquitous in animal learning tasks (see Flaherty, 1982, and Williams, 1983, for recent reviews). The particular focus of the present paper is contrast that occurs in the consumption of sucrose and saccharin solutions. Although these contrast effects may be produced by a variety of experimental procedures, two are of particular relevance. The first of these occurs when animals are given repeated exposure to one reward and then shifted to an alternative reward. For example, if rats are given brief access to $32 \%$ sucrose each day for 10 days and then shifted to $4 \%$ sucrose, they consume about $50 \%$ as much of the $4 \%$ solution as do animals that have experienced only the $4 \%$ sucrose (see, e.g., Becker \& Flaherty, 1983, and Lombardi \& Flaherty, 1978). This contrast, termed a successive negative contrast effect, must be based on a comparison of the $4 \%$ postshift solution with the memory of the preshift $32 \%$ solution (Spear, 1967). If the interval between preshift and postshift solution is long, contrast does not occur (e.g., Gonzalez, Fernhoff, \& David, 1973; Flaherty \& Lombardi, 1977).

A second situation in which contrast may occur, and the one that is the major concern of this paper, is one in which animals are given a series of daily "pairings" of two solutions-in particular, a less preferred solution which precedes a more preferred solution. It has been

Research supported by grants from the Charles and Johanna Busch Memorial Fund and the Rutgers University Research Council. Susan Checke conducted pilot research for this experiment. The idea for a within-subjects experiment arose during a conversation with Ralph Miller of SUNY, Binghamton.

The authors' mailing address is: Department of Psychology, Rutgers University, Busch Campus, New Brunswick, NJ 08903. found that, in this circumstance, the intake of the less preferred solution is suppressed. For example, rats given access to saccharin typically show an acquisition curveintake increases as a function of experience (e.g., Domjan, 1976). However, this acquisition function is suppressed if saccharin access is followed by a brief period of access to $32 \%$ sucrose (Flaherty \& Checke, 1982). No suppression of saccharin intake occurrs if the saccharin is followed by $2 \%$ sucrose.

The suppression of saccharin intake has been attributed to a contrast effect based on a comparison of the preferred $32 \%$ sucrose with the less preferred .15\% saccharin solutions used in these experiments (Flaherty \& Checke, 1982). A question arises, though, as to the locus of the comparison that leads to the contrast. That is, are the animals comparing the saccharin solution received each day with the memory of the $32 \%$ sucrose received the previous day, a comparison which would make the saccharin suppression effect just another case of successive contrast, or are they comparing the saccharin with the $32 \%$ sucrose they will soon receive on that day? This latter possibility would involve the daily anticipation of the preferred solution.

In order to evaluate these two possible loci of comparison, retrograde or anterograde, the intersolution interval was manipulated in several previous experiments. These experiments showed that contrast diminished as the intersolution interval increased in the range of 1 to $30 \mathrm{~min}$. These results were interpreted to mean that the saccharin suppression was based on the anticipation of the impending $32 \%$ solution each day rather than on a retrograde comparison with the $32 \%$ received on the previous day. The rationale for this interpretation was as follows. If the locus of the comparison was the $32 \%$ sucrose received $24 \mathrm{~h}$ earlier, then a change of a few minutes in the daily 
intersolution interval should not have much effect. Since these small changes did reliably reduce contrast, it was assumed that the comparison was based upon a withinday anticipation of the peferred solution, with the intersolution interval functioning, perhaps. analogously to the CS-US interval in standard Pavlovian conditioning procedures.

The present experiment is concerned with another, perhaps more powerful, test of the hypothesis that contrast in this situation is a within-day anterograde process rather than a between-day retrograde process. In this experiment, the different pairings of solutions were manipulated entirely within subjects. That is, the same animals experienced conditions in which a $0.15 \%$ saccharin solution sometimes predicted a subsequent $0.15 \%$ saccharin solution and sometimes predicted a subsequent $32 \%$ sucrose solution. These two conditions were experienced in regular alternation across days. Thus, if the animals received the $0.15 \%-32 \%$ pairing on the 1 st day, they received a $0.15 \%-0.15 \%$ pairing on the 2 nd day, a $0.15 \%$ $32 \%$ pairing on the 3rd day, etc. This arrangement places the two potential loci of control for the contrast effect in direct opposition. That is, if the contrast is based upon the $32 \%$ received on the previous day, then lick-rates for the initial $0.15 \%$ saccharin solution should be lower on days when the animals recieve the $0.15 \%-0.15 \%$ pairings, because these days always follow a $32 \%$ sucrose day. On the other hand, if the locus of control is the within-day anticipation of the solution when the animals receive the $0.15 \%-32 \%$ pairings, then the lick-rate for the $0.15 \%$ solution should be lower on these differential pairing dayswhen the $0.15 \%$ saccharin predicts the $32 \%$ sucrose.

\section{Subjects}

\section{METHOD}

Twelve male Sprague-Dawley-derived rats $(400-520 \mathrm{~g})$ were individually housed under a $14 / 10$ light/dark cycle. They were maintained at $82 \%$ body weight and fed once per day (Purina Lab Chow). Water was available continuously in the home cage. All but one of the rats had completed a glycemic conditioning experiment 30 days before the start of the present experiment.

\section{Apparatus \\ Testing was conducted in three Plexiglas chambers measuring $30 \times 25 \times 25 \mathrm{~cm}$. A $1.5 \mathrm{-cm}$ hole had been drilled in the center of one $30-\mathrm{cm}$ side of each box, $4 \mathrm{~cm}$ from the wire-mesh floor. Solutions were delivered to each box via two motors, which could advance or withdraw graduated cylinders to align the drinking tubes with this opening. Licks were recorded by using a contact relay circuit and microcomputers. The menthol odor was produced with Mentholatum (a commercial pain-relieving ointment).}

\section{Procedure}

All subjects received $.15 \%$ saccharin in the first tube and either $.15 \%$ saccharin or $32 \%$ sucrose in the second tube. These conditions were alternated over days, each condition paired with a different set of stimuli. The cue conditions used were either (1) dim light, tone, no menthol odor, and white noise or (2) bright light, clicking relay, menthol odor, and no white noise.

Pairing of cues with the solution conditions was counterbalanced. For half the subjects, Condition $.15 \%-32 \%$ was paired with the first set of cues (dim light, tone, no odor, white noise) and Condi- tion $.15 \%-.15 \%$ was paired with the second set (bright light, click, menthol odor, and no white noise). For the other half of the subjects, the cue-solution pairings were reversed.

Phase 1. The initial phase of the experiment lasted from Day 1 to Day 20 . Condition . $15 \%-32 \%$ consisted of the following sequence of events: a 3 -min access period to $.15 \%$ saccharin solution, withdrawal of the tube and an interval of $15 \mathrm{sec}$ with no tube available, then $5 \mathrm{~min}$ access to a $32 \%$ sucrose solution. In Condition $.15 \%-.15 \%$, the animals received 3 -min access to a $.15 \%$ saccharin, retraction of that tube, then a $15-\mathrm{sec}$ interval followed by 5 -min access to .15\% saccharin solution. The timing of the access period was initiated by the rat's first lick after a tube became available.

Phase 2. In Phase 2, Days 21-32, the only change was that the intersolution interval was extended to $1 \mathrm{~min}$.

Phase 3. In Phase 3, Days 33-52, the cue-solution pairings were reversed. The animals received a total of 52 days of training, with one pairing of the solutions given each day. Sucrose was mixed by weight (sucrose/sucrose + water) and made $24 \mathrm{~h}$ prior to use from commercial grade cane sugar and tap water. The saccharin solution was mixed on a weight/volume basis from sodium saccharin and tap water.

\section{RESULTS}

Mean licks for the $0.15 \%$ saccharin solution presented in the first tube are shown in Figure 1 for the various stages of the experiment. During Phase 1, the rats licked less for the $0.15 \%$ saccharin on days when the second tube contained $32 \%$ sucrose than on days when the second tube also contained the $0.15 \%$ saccharin solution $[F(1,10)=12.23, p<.01]$. This pattern developed over training with reliable concentration differences appearing in Days 4 and 6-10 [concentration $x$ days, $F(9,86)$ $=2.76, \mathrm{p}<.01$, followed by least significant difference tests]. The same pattern of results was obtained in Phase 2, when the intersolution interval was extended to $1 \min [F(1,10)=78.66, p<.001]$. Finally, in Phase 3, when the cue-reward pairings were reversed, there was

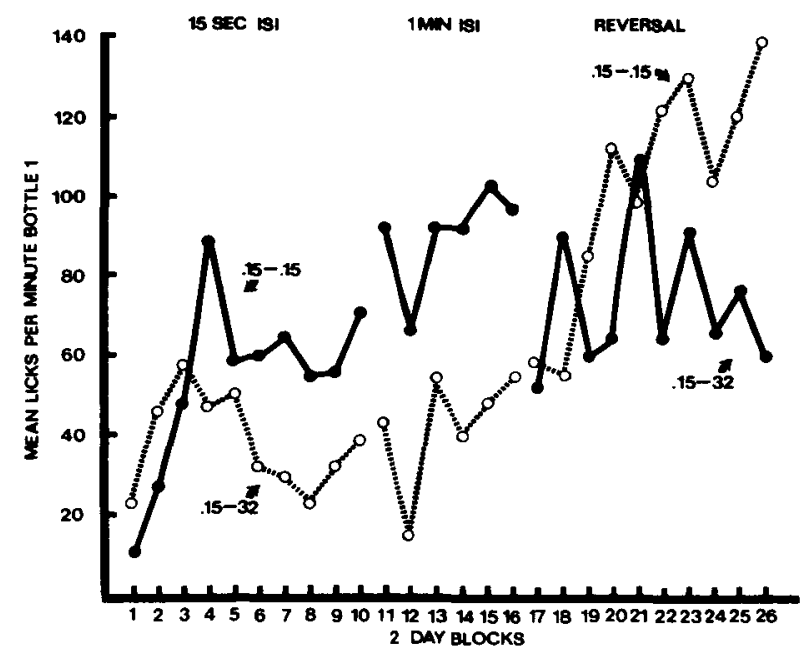

Figure 1. Lick rate for $0.15 \%$ saccharin on the first tube as a function of the solution in the second tube $(0.15 \%$ saccharin or $32 \%$ sucrose) and stage of the experiment. 


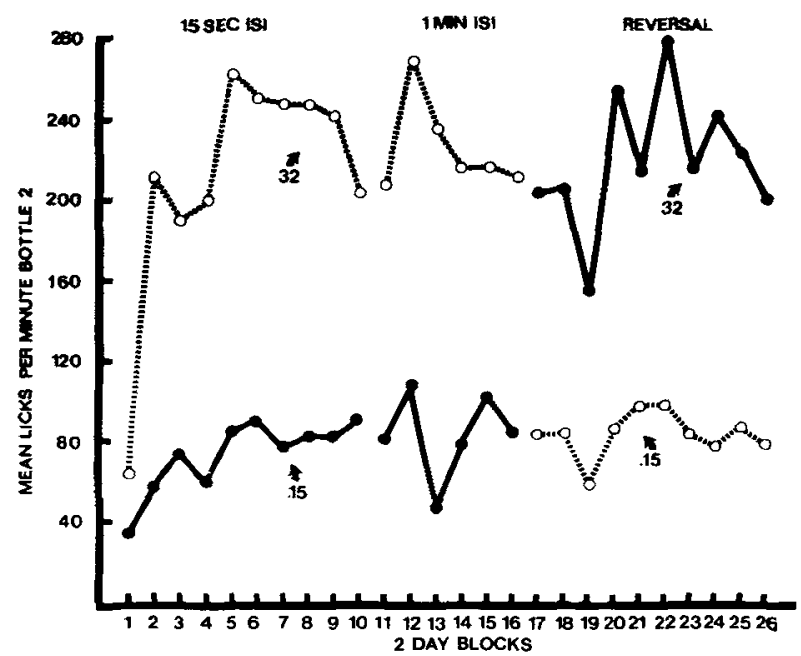

Figure 2. Lick rate for solutions available in the second tube $(0.15 \%$ saccharin or $32 \%$ sucrose).

an initial loss of the discrimination followed by a reversal such that the animals again licked less $0.15 \%$ saccharin when it predicted sucrose than when it predicted more saccharin [solution $\times$ day, $F(9,78)=3.08, p<.01$; soIution, $\mathrm{F}(1,10)=46.70, \mathrm{p}<.001$, over the last 6 days]. The precipitous drop in lick frequency on the 1 st day of reversal was probably due to the fact that this was the first, and only, day on which the animals experienced the same cue events on 2 consecutive days.

The effect of the cues per se was not reliable in any of the three phases of the experiment [Phase 1, F(1,10) $=1.91, \mathrm{p}>.05$; Phase $2, \mathrm{~F}(1,10)=2.20, \mathrm{p}>.05$; Phase 3, $\mathrm{F}(1,10)=3.23, \mathrm{p}>.05]$.

Licks on the second tube were reliably higher when the second tube contained $32 \%$ sucrose than when it contained $0.15 \%$ saccharin in all three phases of the experiment [Phase 1, F $(1,10)=79.29, \mathrm{p}<.001$; Phase $2, \mathrm{~F}(1,10)$ $=56.57, \mathrm{p}<.001$; Phase $3, \mathrm{~F}(1,10)=30.71, \mathrm{p}<$ $.002]$. These data are presented in Figure 2. Lick rate (licks/minute) was also higher on the second tube than on the first tube when the second tube contained $32 \%$ sucrose and the first tube contained $0.15 \%$ saccharin [solution $\times$ bottle; Phase $1, F(1,10)=68.19, p<.01$; Phase 2, $F(1,10)=129.51, p<.001 ;$ Phase 3, $F(1,10)$ $=66.33, \mathrm{p}<.001$; followed by least significant difference tests]. However, lick rates (licks/minute) on the two tubes were not different when both contained the $0.15 \%$ saccharin solutions (same $F$ values as above, followed by least significant difference tests).

\section{DISCUSSION}

In a series of experiments, we examined the effects of single daily pairings of a brief access period to $0.15 \%$ saccharin and brief access periods to a second solution presented a short time after the initial saccharin exposure. Previous studies had shown that the intake of a $0.15 \%$ saccharin solution was suppressed when that solution preceded the later availability of $32 \%$ sucrose but not when the saccharin preceded the later availability of $2 \%$ sucrose. These earlier studies also showed that the degree of saccharin suppression was reduced as the interval between the daily presentation of solution pairs increased (Flaherty \& Checke, 1982). These results were interpreted to mean that the animals learned the predictive relationship between the two solutions and that intake of the initial solution was suppressed when it predicted a more preferred solution. The effects produced by variations in the intersolution interval argued against the possibility that the saccharin intake was suppressed by a comparison of the saccharin with the memory of the $32 \%$ sucrose received on the previous day. That is, the intersolution interval data favored an interpretation in terms of anticipatory processes rather than in terms of a retroactive successive contrast.

The results of the present experiment show that supressed intake of an initial saccharin solution can be obtained within subjects on days when one set of cues signal that the second solution will be $32 \%$ sucrose as compared to days when another set of cues signal that the second solution will be $0.15 \%$ saccharin. These results support an interpretation in terms of anticipatory processes for the following reason. The two different pairing conditions, $0.15 \%$ saccharin preceding $32 \%$ sucrose and $0.15 \%$ saccharin preceding $0.15 \%$ saccharin, occurred in daily alternation. If contrast (suppressed intake of the initial saccharin solution) had been based on the comparison with the $32 \%$ received on the previous day, then saccharin intake should have been lower on the $0.15 \%-0.15 \%$ days, since these pairing conditions always followed a $0.15 \%-32 \%$ day. The fact that this was not the case, and that intake of the initial saccharin solution was lower on the $0.15 \%-32 \%$ days, indicates that the locus of the comparison is within day, not between days.

The present paradigm seems analogous to a Pavlovian conditioning situation in that the regular pairing of two events alters the nature of the response to the first of these events. In addition, this alteration is dependent upon the length of the interval between the two events (Flaherty $\&$ Checke, 1982). A difference between the present procedure and standard conditioning is that some behavior on the part of the animal is necessary to obtain both the "CS" and the "US." Of course, in many conditioning procedures, some behavior on the part of the subject is necessary to obtain the US (e.g., Jenkins, Barrera, Ireland, \& Woodside, 1978; Zener, 1937). And, in the conditioning aversion procedure, behavior on the part of the subject is necessary to obtain the CS (e.g, Garcia \& Koelling, 1966). A second difference between the present procedure and the usual conditioning situation is that the "CS" in these experiments is not neutral; it has incentive value. This incentive value is apparently modified by the regular daily pairings of the two solutions. The fact that the "CS" has incentive value is also true in the conditioned aversion procedure, and this incentive value is also ap- 
parently modified by the pairing process. It is interesting, though, that in both the present procedure and the conditioned aversion procedure the intake of the first substance is reduced by the pairing manipulation, although the US is noxious in the conditioned aversion experiment and preferred in the present procedure.

The fact that a preferred second substance reduces intake of the initial substance shows that the second solution (32\% sucrose) is not functioning as a reinforcer in the usual sense of the term. That is, even though it is preferred to the saccharin and even though access to the sucrose is contingent upon licking of the saccharin (the second tube will not become available unless at least one lick is made to the first tube), intake of the saccharin is suppressed, not elevated, by access to the sucrose.

Our interpretation of these data, including the failure to obtain a reinforcement effect, is as follows. The animals learn the contingent relationship between the two solutions (Rescorla, 1968) and, once this learning is completed, the sampling of the first substance serves as a cue for the anticipation of the second-perhaps through a CSelicited representation of the second substance (e.g., Pearce \& Hall, 1980; Rescorla, 1978; Wagner, 1981). This representation of a preferred second substance may serve to devalue the first substance (Holland \& Rescorla, 1975). This interpretation is consonant with aspects of Garcia's interpretation of conditioned food aversions. That is, the pairing of a toxin with a positively valued CS reduces the hedonic value of that CS (Garcia, Hankins, \& Rusiniak, 1974). This interpretation is also consistent with many recent studies which indicate that anticipation of events that are more or less rewarding than a currently experienced stimulus alters responsitivity to that stimulus (e.g., Capaldi, Nawrocki, \& Verry, 1983; Chen \& Amsel, 1980; Hulse \& O'Leary, 1982; Williams, 1976, 1981, 1983).

\section{REFERENCES}

Becker, H. C., \& Flaherty, C. F. (1983). Chlordiazepoxide and ethanol additively reduce gustatory negative contrast. Psychopharamacology, 80, 35-37.

Capaldi, E. J., Nawrocki, T. M., \& Verry, D. R. (1983). The nature of anticipation: An inter- and intraevent process. Animal Learning \& Behavior, 11, 193-198.

Chen, J. S., \& AMSEL, A. (1980). Recall (versus recognition) of taste and immunization against aversive taste anticipation based on illness. Science, 209, 831-833.

Domjan, M. (1976). Determinants of the enhancement of flavored-water intake by prior exposure. Journal of Experimental Psychology: Animal Behavior Processes, 2, 17-27.
Flaherty, C. F. (1982). Incentive contrast: A review of behavioral changes following shifts in reward. Animal Learning \& Behavior, 10, 409-440.

Flaherty, C. F., \& Checke, S. (1982). Anticipation of incentive gain. Animal Learning \& Behavior, 10, 177-182.

FlaherTy, C. F., \& LOMBaRDi, B. R. (1977). Effect of prior differential taste experience on retention of taste quality. Bulletin of the Psychonomic Society, 9, 391-394.

Garcia, J., Hankins, W. G., \& Rusiniak, K. W. (1974). Behavioral regulation of the milieu interne in man and rat. Science, 185, 824-831.

Garcia, J., \& Koelling, R. A. (1966). The relation of cue to consequence in avoidance learning. Psychonomic Science, 4, 123-124.

Gonzalez, R. C., Fernhoff, D., \& David, F. G. (1973). Contrast, resistance to extinction, and forgetting in rats. Journal of Comparative and Physiological Psychology, 84, 562-571.

Holland, P. C., \& Rescorla, R. A. (1975). The effects of two ways of devaluing the unconditioned stimulus after first- and second-order appetitive conditioning. Journal of Experimental Psychology: Animal Behavioral Processes, 1, 355-363.

Hulse, S. H., \& O'LearY, D. (1982). Serial pattern learning: Teaching an alphabet to rats. Journal of Experimental Psychology: Animal Behavioral Processes, 8, 260-273.

Jenkins, H. M., Barrera, F. J., Ireland, C., \& WoOdside, B. (1978). Signal-centered action patterns of dogs in appetitive classical conditioning. Learning and Motivation, 9, 272-296.

Lombardi, B. R., \& FlaherTy, C. F. (1978). Apparent disinhibition of successive but not of simultaneous negative contrast. Animal Learning \& Behavior, 6, 30-42.

Pearce, J. M., \& Hall, G. (1980). A model of Pavlovian learning: Variations in the effectiveness of conditioned but not unconditioned stimuli. Psychological Review, 87, 532-552.

Rescorla, R. A. (1968). Probability of shock in the presence and absence of CS in fear conditioning. Journal of Comparative and Physiological Psychology, 66, 1-5.

Rescorla, R. A. (1978). Some implications of a cognitive perspective on Pavlovian conditioning. In S. H. Hulse, H. Fowler, \& W. K. Honig (Eds.), Cognisive processes in animal behavior, Hillsdale, NI: Erlbaum.

SPEAR, N. E. (1967). Retention of reinforcer magnitude. Psychological Review, 74, 216-234.

WAGNER, A. R. (1981). SOP: A model of automatic memory processing in animal behavior. In N. E. Spear \& R. R. Miller (Eds.), Information processing in animals: Memory mechanisms. Hillsdale, $\mathrm{NJ}$ : Erlbaum.

Williams, B. A. (1976). Behavioral contrast as a function of the temporal location of reinforcement. Joumal of the Experimental Analysis of Behavior, 26, 57-64.

Williams, B. A. (1981). The following schedule of reinforcement as a fundamental determinant of steady state contrast in multiple schedules. Journal of the Experimental Analysis of Behavior, 35, 293-310.

Williams, B. A. (1983). Another look at contrast in multiple schedules. Journal of the Experimental Analysis of Behavior, 39, 345-384.

ZENER, K. (1937). The significance of behavior accompanying conditioned salivary secretion for theories of the conditioned response. American Journal of Psychology, 50, 384-403.

(Manuscript received June 19, 1984; revision accepted for publication August 27, 1984.) 